\title{
Continuous professional competence (CPC) for emergency medical technicians in Ireland: educational needs assessment
}

\author{
Shane Knox ${ }^{1,2}$, Walter Cullen ${ }^{1}$ and Colum Dunne ${ }^{1 *}$
}

\begin{abstract}
Background: As in other countries, the Irish Regulator for Pre-Hospital practitioners, the Pre-Hospital Emergency Care Council (PHECC), will introduce a Continuous Professional Competence (CPC) framework for all Emergency Medical Technicians (EMTs), Paramedics and Advanced Paramedics (APs). This framework involves EMTs participating in regular and structured training to maintain professional competence and enable continuous professional developments. To inform the development of this framework, this study aimed to identify what EMTs consider the optimum educational outcomes and activity and their attitude towards CPC.
\end{abstract}

Methods: All EMTs registered in Ireland $(n=925)$ were invited via email to complete an anonymous online survey. Survey questions were designed based on Continuous Professional Development (CPD) questionnaires used by other healthcare professions. Quantitative and qualitative analyses were performed.

Results: Response rate was $43 \%(n=399) .84 \%$ of participants had been registered in Ireland for less than 24 months, while 59\% had been registered EMTs for more than one year. Outcomes were: evidence of CPC should be a condition for EMT registration in Ireland (95\%), 78\% believed that EMTs who do not maintain CPC should be denied the option to re-register. Although not required to do so at the time of survey, $69 \%$ maintained a professional portfolio and 24\% had completed up to 20 hours of CPC activities in the prior 12 months. From a list of 22 proposed CPC activities, 97\% stated that practical scenario-based exercises were most relevant to their role. E-learning curricula without practical components were considered irrelevant (32\%), but the majority of participants (91\%) welcomed access to e-learning when supplemented by related practical modules.

Conclusion: EMTs are supportive of CPC as a key part of their professional development and registration. Blended learning, which involves clinical and practical skills and e-learning, is the optimum approach.

Keywords: Emergency medical technicians, Continuous professional development, CPD, Blended learning, E-learning, Educational, Ambulance

\section{Background}

Pre-hospital care in Ireland is provided by the Health Service Executive's (HSE) National Ambulance Service (NAS) and (in parts of Dublin city) the 'Dublin Fire Brigade'. Staff who respond to pre-hospital incidents are all trained to Paramedic or Advanced Paramedic (AP) level. In addition, pre-hospital care is provided at sporting and other public events by Emergency Medical Technicians

\footnotetext{
* Correspondence: colum.dunne@ul.ie

${ }^{1}$ Centre for Interventions in Infection, Inflammation \& Immunity (4i) and Graduate Entry Medical School, University of Limerick, Limerick, Ireland Full list of author information is available at the end of the article
}

(EMTs), mostly within the voluntary organisations: Civil Defence, Order of Malta Ireland, St. John Ambulance and the Irish Red Cross. All of these practitioners are registered with the regulating authority, Ireland's Pre-Hospital Emergency Care Council (PHECC) [1].

Currently, once registered as a practitioner with PHECC there is no requirement to show evidence of competence, other than annual certification in Cardiopulmonary Resuscitation (CPR). In order to re-register practitioners must also complete a self-declaration form stating that they are currently practicing, are of good character and in good health and will commit to the PHECC Code of Conduct

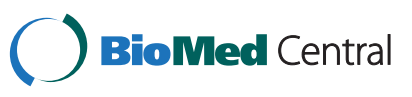


and Ethics. There is no current requirement to show evidence of any patient contacts, or to maintain a learning portfolio, or participate in skill maintenance programmes. PHECC licences are issued yearly, while re-registration occurs every three years.

In 1993, a report from the Irish government [2] stated that the ambulance service "forms a valued and integral part of the emergency services" and "was used as an extension of the hospital service with the objective of getting the patient into hospital as quickly as possible so that advanced medical treatment could be provided by a medical practitioner", thus implying: 1) that advanced medical treatment could only commence within a hospital and 2) that the only purpose of the ambulance service was to provide transport for patients. The same report further recommended significant improvement in the quality of training provided to ambulance personnel. Reflecting its most recent iteration, this recommendation is furthered in the PHECC strategic plan (2011-2014) where the need to develop and implement a continuing professional competence (CPC) framework was stated [3]. However, translating advances in care guidelines into actual care delivered to patients poses many challenges associated with the effective acquisition of new knowledge and practical skills in addition to maintenance of existing expertise.

Previous studies have assessed Paramedic and Advanced Paramedic training and continuing education in Ireland [4-7]. However, in this study, we wished to determine, for the first time, the attitudes of EMTs in Ireland towards $\mathrm{CPC}$, their suggested outcomes / preferred delivery format and relevance to their roles. We devised a short answer survey, based on similar questionnaires used by other professions [8-12], to determine current EMT demographics, CPC activities, and attitudes towards effectiveness of the varying training methods employed. It is hoped that this information will inform future CPC programme development.

\section{Methods}

\section{Participants}

In July and August 2012, all EMTs licensed to practice in Ireland and registered with the Pre-hospital Emergency Care Council's (PHECC) $(n=925)$ were contacted by email. Questions were entered into a Survey Monkey ${ }^{\mathrm{mm}}$ online questionnaire (www.surveymonkey.com). A link was provided to the survey and to a concise, unbiased explanation of the survey topic. Participation was voluntary and anonymous. Consent to participate was recorded. Conduction of the study and its design, taking into consideration published healthcare professions' questionnaires relating to continuous professional development (CPD) $[9-11,13]$, were approved by the Ethics Committee of the Faculty of Education and Health Sciences, University of Limerick, Ireland and the Research Ethics Committee of the Health Services Executive Mid-Western Regional Hospital, Limerick, Ireland.

\section{Data collection and analysis}

Health professionals are increasingly expected to identify their own learning needs through self-assessment [14,15]. Therefore, the survey questions were designed to elicit participants' views on CPC and, so, the survey was piloted following a presentation on CPC to 120 registered EMTs at a biannual conference in 2011 [16]. Responses were recorded (included audio recording) and summarised at the event using mind mapping software [17]. Following analysis of the exercise, the design of the questionnaire was finalised and trialled using 12 EMTs who were subsequently excluded from the analyses.

The questionnaire (see Additional file 1) comprised questions relating to demographics, opinions on $\mathrm{CPC}$, registration and also included a matrix of 22 listed activities whereby participants were asked to indicate how relevant they believed each activity was to CPC. Some of the activities related to education generally, while others related specifically to pre-hospital practice. There were 26 items in the questionnaire. Not every single question was answered by every respondent and, therefore, answers are described by number and percentage of responses to specific questions. The data were downloaded from Survey Monkey ${ }^{\text {mix }}$ software to an electronic data file and quantitative analysis was performed using Statistical Packages for the Social Sciences (SPSS version 20.0).

\section{Results}

\section{Demographics}

$399 / 925$ responses were received (43\% of all registered EMTs), of whom 271 (68\%) were Male; 115 (29\%) were Female and 13 (3\%) did not report gender. Table 1 compares the Age category with Gender.

However, while responses were reasonably well dispersed (Figure 1) across the voluntary organisations: i.e., Order of Malta (96, 24\%), Civil Defence (80, 20\%), St. John Ambulance Brigade (29, 7\%) and the Irish Red Cross $(97,24 \%)$, there was considerably less participation by EMTs employed by the Irish State (10\%) such as the Permanent Defence Forces, Irish Health Service, An Garda Síochána (Police), etc and private ambulance services $9.7 \%$. It should be noted that there were very few EMTs within these organisations at the time of the survey (as they are not employed in their permanent position as EMTs but may have completed the programme independently).

A total of 325 (84\%) of respondents were registered EMTs for two years or less (Table 2), with almost half of those (161) being registered for less than one year. Respondents who had been with their organisation for less 
Table 1 Gender and age group

\begin{tabular}{|c|c|c|c|c|c|c|c|c|c|}
\hline & & & \multicolumn{5}{|c|}{ Please select your appropriate age group } & \multirow[t]{2}{*}{ Total } & \multirow{2}{*}{$\begin{array}{l}\text { All EMTs with emails } \\
\text { registered with PHECC } \\
(\mathrm{N}=925)\end{array}$} \\
\hline & & & 18- 21 & $22-29$ & $30-39$ & $40-49$ & Over 50 & & \\
\hline \multirow[t]{6}{*}{ Gender } & Male & Count & 9 & 61 & 82 & 64 & 55 & 271 & \\
\hline & & $\%$ within age group & $69.2 \%$ & $66.3 \%$ & $70.1 \%$ & $77.1 \%$ & $67.9 \%$ & $68 \%$ & \\
\hline & & $\%$ of total & $2.3 \%$ & $15.8 \%$ & $21.2 \%$ & $16.6 \%$ & $14.2 \%$ & $68 \%$ & $69 \%(634)$ \\
\hline & Female & Count & 4 & 31 & 35 & 19 & 26 & 115 & \\
\hline & & $\%$ within age group & $30.8 \%$ & $33.7 \%$ & $29.9 \%$ & $22.9 \%$ & $32.1 \%$ & $29 \%$ & \\
\hline & & $\%$ of total & $1.0 \%$ & $8.0 \%$ & $9.1 \%$ & $4.9 \%$ & $6.7 \%$ & $29 \%$ & $31 \%(291)$ \\
\hline \multirow{2}{*}{\multicolumn{2}{|c|}{ Total }} & Count & 13 & 92 & 117 & 83 & 81 & $386\left(\mathrm{DNRG}^{*}\right) 13$ & \\
\hline & & $\%$ of total & $3.4 \%$ & $23.8 \%$ & $30.3 \%$ & $21.5 \%$ & $21.0 \%$ & $100.0 \%$ & $100 \%$ (925) \\
\hline
\end{tabular}

DNRG* - Did not report gender.

than five years represented $33 \%(n=131)$ of the total surveyed, while $28 \%(n=113)$ of those with less than five years service within their organisation had been registered as EMTs for less than two years. 21\% of respondents had over 20 years experience with their respective organisations while $34 \%$ had less than six years service. 30-39 year old respondents represented 30\% $(n=118)$ of the total responses and also represented the largest age group of those with their Organisation for less than five years.

\section{Attitudes towards continuous professional competence}

CPC is considered extremely important by $86 \%(n=343)$ of the EMTs surveyed. $82 \%(n=329)$ agreed that all EMTs should maintain evidence of CPC activities. A total of $61 \%$ $(n=243)$ agreed that CPC is the sole responsibility of the registered practitioner (strongly agreed 26\%, $\mathrm{n}=104$ and agreed $35 \%, n=139)$. Over $78 \%$ of respondents $(n=313)$ believed that their organisation should have input, at least to some extent, into what components should constitute an individual's $\mathrm{CPC}$, with only $7 \%(\mathrm{n}=26)$ stating that the organisation should not have input. Of the EMTs surveyed, $(39 \%, \mathrm{n}=154)$ disagreed that only the regulatory body (PHECC) should determine the structure of CPC components, while $26 \%(n=105)$ agreed that only the PHECC should determine the structure of CPC.

\section{Linking continuous professional competence activities and registration}

The majority of EMTs surveyed (69\%, 220/321), although not obligated, maintained a professional portfolio at the time of the survey (Table 3), with $24 \%(\mathrm{n}=97)$ stating that they had completed up to 20 hours of CPC over the previous 12 -month period. $11 \%(n=43)$ claimed that they had completed over 100 hours of CPC in the same period. Notably, almost a quarter $(23 \%, \mathrm{n}=91)$ of those who had completed their CPC in the previous year had funded participation themselves, while $29 \%(n=116)$ had their costs covered by their organisation either partially $(12 \%, n=46)$ or in full $(18 \%, \mathrm{n}=70)$. When queried as to appropriate levels of CPC required, given a range of choices: 20 hours; 21-40 hours; 41-60 hours; 61-80 hours and 81-100 hours almost $40 \%(n=159)$ believed that an EMT should complete 20-40 hours annually (a combination of the first

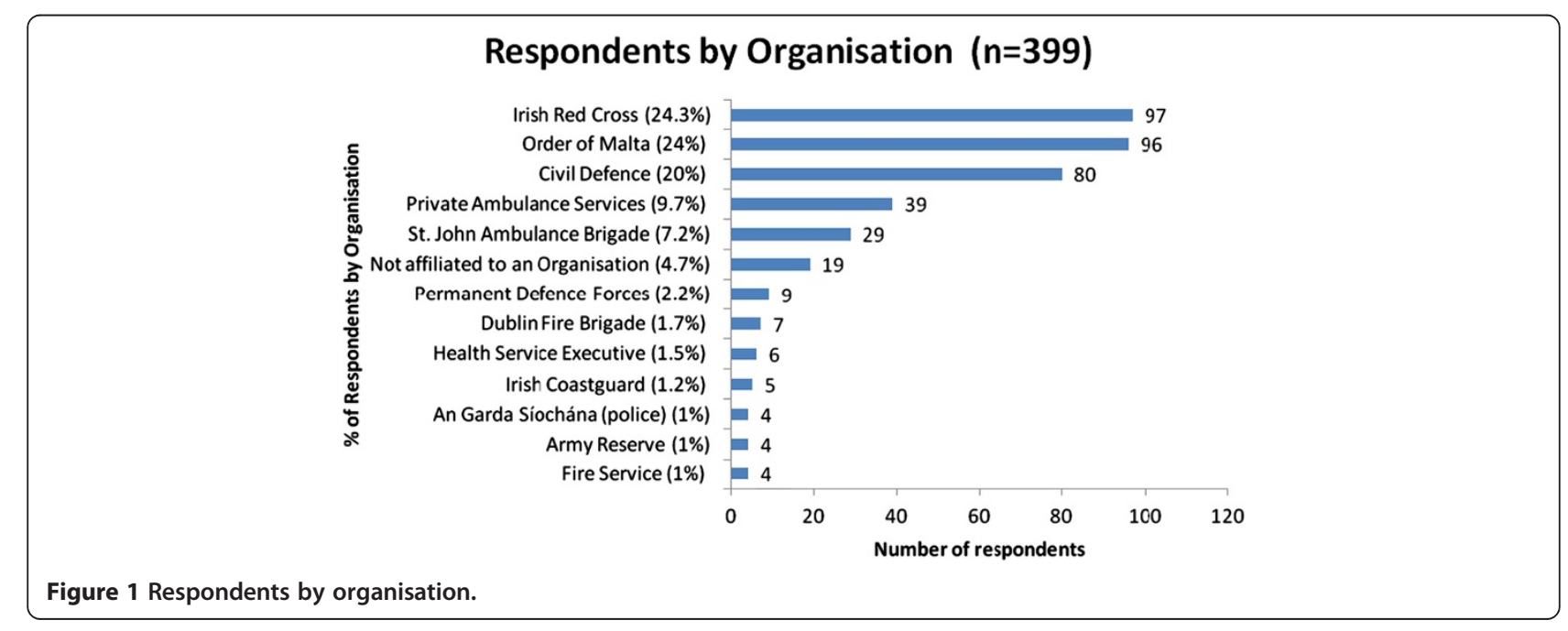


Table 2 Participants' length of service and registration with regulatory authority

\begin{tabular}{|c|c|c|c|c|c|c|c|c|}
\hline & & & \multicolumn{5}{|c|}{ Registration with the pre-hospital emergency care council (PHECC) } & \multirow[t]{2}{*}{ Total } \\
\hline & & & Up to 1 year & $1-2$ years & $3-4$ years & $5-6$ years & More than 6 years & \\
\hline \multirow{10}{*}{$\begin{array}{c}\text { Years with current } \\
\text { organisation }\end{array}$} & $0-5$ & Count & 68 & 45 & 17 & 1 & 0 & 131 \\
\hline & & $\%$ of total & $17.6 \%$ & $11.7 \%$ & $4.4 \%$ & $.3 \%$ & $.0 \%$ & $33.9 \%$ \\
\hline & $6-10$ & Count & 43 & 28 & 16 & 1 & 0 & 88 \\
\hline & & $\%$ of total & $11.1 \%$ & $7.3 \%$ & $4.1 \%$ & $.3 \%$ & $.0 \%$ & $22.8 \%$ \\
\hline & $11-15$ & Count & 22 & 34 & 4 & 1 & 0 & 61 \\
\hline & & $\%$ of total & $5.7 \%$ & $8.8 \%$ & $1.0 \%$ & $.3 \%$ & $.0 \%$ & $15.8 \%$ \\
\hline & $16-20$ & Count & 8 & 16 & 2 & 0 & 0 & 26 \\
\hline & & $\%$ of total & $2.1 \%$ & $4.1 \%$ & $.5 \%$ & $.0 \%$ & $.0 \%$ & $6.7 \%$ \\
\hline & over 20 & Count & 20 & 41 & 13 & 0 & 6 & 80 \\
\hline & & $\%$ of total & $5.2 \%$ & $10.6 \%$ & $3.4 \%$ & $.0 \%$ & $1.6 \%$ & $20.7 \%$ \\
\hline \multirow{2}{*}{\multicolumn{2}{|c|}{ Total }} & Count & 161 & 164 & 52 & 3 & 6 & 386 \\
\hline & & $\%$ of total & $41.7 \%$ & $42.5 \%$ & $13.5 \%$ & $.8 \%$ & $1.6 \%$ & $100.0 \%$ \\
\hline
\end{tabular}

Table 3 Attitudes towards CPC and linking CPC activities and registration

\begin{tabular}{|c|c|c|}
\hline Attitudes towards continuous professional competence (CPC) & Agree & Number of responses \\
\hline CPC is extremely important to me & $86 \%$ & 343 \\
\hline EMTs should maintain evidence of CPC activities & $82 \%$ & 329 \\
\hline CPC is the sole responsibility of the registered practitioner & $61 \%$ & 243 \\
\hline Your organisation should have some input into your CPC & $78 \%$ & 313 \\
\hline Only PHECC should determine the structure of CPC & $26 \%$ & 105 \\
\hline \multicolumn{3}{|l|}{ Linking CPC activities and registration } \\
\hline Currently maintain a professional portfolio & $69 \%$ & $220 / 321$ \\
\hline \multicolumn{3}{|l|}{ How many hours of CPC have you completed over the previous 12 - month period? } \\
\hline Up to 20 hours & $24 \%$ & 97 \\
\hline Over 100 hours & $11 \%$ & 43 \\
\hline \multicolumn{3}{|l|}{ Who paid for your CPC over the previous 12-month period? } \\
\hline Self-funded & $23 \%$ & 91 \\
\hline Paid for by your Organisation - in full & $18 \%$ & 70 \\
\hline Paid for by your Organisation - partially & $12 \%$ & 46 \\
\hline How many hours of CPC activities do you think would be appropriate for EMTs in a 12-month period? & Agree & Number of responses \\
\hline 20 hours & $14 \%$ & 58 \\
\hline $21-40$ hours & $25 \%$ & 101 \\
\hline $41-60$ hours & $17 \%$ & 69 \\
\hline $61-80$ hours & $8 \%$ & 31 \\
\hline 81-100 hours & $8 \%$ & 34 \\
\hline Other & $9 \%$ & 37 \\
\hline Skipped question & $17 \%$ & 69 \\
\hline $\begin{array}{l}\text { EMTs who do not maintain their CPC and who continue not to meet the requirements, should not be allowed } \\
\text { to re-register as an EMT }\end{array}$ & $78 \%$ & $273 / 352$ \\
\hline Evidence of CPC should be a condition for EMT registration & $95 \%$ & $341 / 359$ \\
\hline Registration as an EMT with PHECC is of personal importance & $95 \%$ & 381 \\
\hline
\end{tabular}


two categories), with only $8 \%(n=34)$ stating that $81-$ 100 hours would be appropriate.

Over 78\% (273/352) of the EMTs surveyed stated that EMTs who do not maintain their CPC and continue not to meet the requirements, should not be allowed to reregister. $95 \%$ of respondents either strongly agreed $(61 \%$, $218 / 359)$, or agreed $(34 \%, 123 / 359)$, that evidence of CPC should be a condition for EMT registration. 95\% $(\mathrm{n}=381)$ stated that registration with PHECC was of personal importance to them.

\section{Consultation regarding specific continuous professional competence activities}

Most respondents considered practical type learning relevant (Table 4): training on a simulation manikin 92\% (297/ $321)$, regular practical assessments 79\% (253/319); Cardiac First Response (CFR/CPR) re-validation 97\% (311/322); practical training scenarios 97\% (313/321); completing a duty with paramedics/advanced paramedics 95\% (306/321) and Annual Major Incident exercises 92\% (297/319).

With regard to access to e-learning followed by related practice: $91 \%$ of respondents $(291 / 320)$ believed this to be very relevant $(45 \%, n=145)$ or relevant $46 \%(n=146)$; compared with 'e-learning modules only and no related practice being very relevant $9 \%(n=29)$ and relevant $26 \%(n=80)$. 'E-Learning modules only and no related practice' recorded the highest 'Very Irrelevant' (8\%, 27/ $313) /$ 'irrelevant' 24\% (74/313) responses from all categories with a combined total of $32 \%(101 / 313)$ claiming it has no relevance.

In addition to the practical-type, hands-on activities preferred for CPC maintenance, EMTs also considered the following activities very relevant or relevant in maintaining Continuous Professional Competence: courses accredited by PHECC 96\% (307/319); keeping a learning portfolio 90\% (288/319); mentoring others 87\% (277/317); lecturing/teaching $86 \%$ (276/319); being a Tutor $79 \%$ (251/316); attending relevant conferences $78 \%$ (246/317); appraisal with a senior EMT officer (or above) 78\% (248/ $319)$; case study review 64\% (204/317); being an examiner $69 \%$ (222/319); appraisal with a doctor/medical supervisor 65\% (207/320); first aid competitions 50\% (159/315); project work 48\% (152/318); appraisal of a journal publication $39 \%(124 / 316)$.

Table 4 Relevance of potential CPC activities

\begin{tabular}{|c|c|c|c|c|c|}
\hline \multirow{2}{*}{$\begin{array}{l}\text { Very relevant/relevant }=\text { relevant not relevant/very } \\
\text { irrelevant }=\text { not relevant }\end{array}$} & \multicolumn{2}{|c|}{ Relevant } & \multicolumn{2}{|c|}{ Not relevant } & \multirow[b]{2}{*}{$\begin{array}{l}\text { Total response to } \\
\text { question }\end{array}$} \\
\hline & Responses & $\begin{array}{l}\% \text { of total } \\
\text { responses }\end{array}$ & Responses & $\begin{array}{l}\% \text { of total } \\
\text { responses }\end{array}$ & \\
\hline Practical training scenarios & 313 & $97 \%$ & 2 & $0.6 \%$ & 321 \\
\hline Annual cardiac first response/CPR revalidation & 311 & $97 \%$ & 6 & $2 \%$ & 322 \\
\hline Attending courses accredited by PHECC & 307 & $96 \%$ & 2 & $0.6 \%$ & 319 \\
\hline Doing a duty with paramedics/advanced paramedics & 306 & $95 \%$ & 7 & $2 \%$ & 321 \\
\hline Major Incident/emergency exercises & 297 & $93 \%$ & 7 & $2 \%$ & 319 \\
\hline Training on a simulation manikin & 297 & $92 \%$ & 7 & $2 \%$ & 321 \\
\hline Access to e-learning followed by related practice & 291 & $91 \%$ & 5 & $2 \%$ & 320 \\
\hline Keeping a portfolio of CPC activities & 288 & $90 \%$ & 4 & $1 \%$ & 319 \\
\hline Mentoring others & 277 & $87 \%$ & 12 & $4 \%$ & 317 \\
\hline Lecturing/teaching & 276 & $86 \%$ & 15 & $5 \%$ & 319 \\
\hline Access to medical journals/medical books & 266 & $83 \%$ & 11 & $3 \%$ & 320 \\
\hline Regular practical assessments & 253 & $79 \%$ & 13 & $4 \%$ & 319 \\
\hline Being a tutor & 251 & $79 \%$ & 19 & $6 \%$ & 316 \\
\hline Appraisal with senior EMT Officer (or above) & 248 & $78 \%$ & 20 & $6 \%$ & 319 \\
\hline Relevant conferences e.g RESUS & 246 & $78 \%$ & 18 & $6 \%$ & 317 \\
\hline Being an examiner & 222 & $69 \%$ & 30 & $9 \%$ & 319 \\
\hline Appraisal with a doctor/medical supervisor & 207 & $65 \%$ & 37 & $11 \%$ & 320 \\
\hline Case study review & 204 & $64 \%$ & 20 & $6 \%$ & 317 \\
\hline First aid competitions & 159 & $50 \%$ & 78 & $25 \%$ & 315 \\
\hline Project work & 152 & $48 \%$ & 50 & $16 \%$ & 318 \\
\hline Appraisal of journal publications & 124 & $39 \%$ & 62 & $20 \%$ & 316 \\
\hline e-learning modules only and no related practice & 109 & $35 \%$ & 101 & $32 \%$ & 313 \\
\hline
\end{tabular}




\section{Discussion}

Whilst there is evidence of competence and CPD programmes within ambulance services internationally (e.g., Norway [18], Australia [19], UK [20], Canada [21]), the evidence of any consultation with practitioners prior to the introduction of such programmes is scarce.

EMTs must embrace the multitude of activities that contribute to a professional's development and the outcome of good CPD should be practitioners with increased competence and improved patient care [22]. This is the first study of attitudes towards professional competence among EMTs in Ireland and indicates that there appears to be a genuine enthusiasm for the introduction of CPC and a positive link to professionalism, similar to other healthcare professions $[9,11,12,23-26]$. This enthusiasm towards CPC is reinforced further as a significant number of EMTs are already maintaining a learning portfolio and participating in CPC activities, as the vast majority of participants agreed that $\mathrm{CPC}$ should be a requirement for PHECC registration and as $95 \%$ believed that registration with PHECC is of personal importance to them. This view of CPD being a requirement for registration is supported by legislation for some professions [27-29] or shown in previous studies to be shared by practitioners themselves $[26,30]$.

\section{E-learning}

E-learning is the use of internet technologies to enhance knowledge and performance [31]. There are many formats in which e-learning is delivered and many terms synonymous with e-learning, such as web-based (WBL) or on-line learning. One of the advantages of elearning is that it can be synchronous or asynchronous and, therefore, can be flexible and particularly attractive for pre-hospital practitioners. In Ireland, PHECC has progressed the use of on-line examinations and learning modules since its formation. Indeed, Irish EMT examinations are delivered partially via an electronic software programme. Most Health Professions regulators tend to accredit and set standards in training rather than develop training $[32,33]$ and, so, the e-learning approach (albeit blended with practical instruction provided by the training institutions) utilised most recently by PHECC to allow paramedics and APs complete on-line learning modules is unusual. Furthermore, this training methodology had not been in place for the initial training of EMTs surveyed and, taking cognisance of the survey results, it would appear that EMTs might use e-learning followed by practical reinforcement, but would appear less eager to use e-learning alone as a means to maintain competence.

Our survey included 22 potential CPC activities (see Table 4) and asked which activities did EMTs believe were relevant/irrelevant. The results showed that practical, hands-on activities were preferred over theoretical/non-practice type activities. Also, there were less negative responses regarding activities related to practical skills than to theoretical skills. This further substantiates the case for practical, hands-on activities, whether as a standalone activity or coupled with the e-learning approach. The EMTs surveyed in this study seemed to share the view of Ruiz et al in that perhaps they did not value e-learning as a replacement for traditional instructorled training but rather as a complement to it, forming part of a blended-learning strategy [31]. EMTs function in environments that require lateral thinking [34]. Arguably, variation in learning methodologies could be encouraged so to facilitate the variations in personal learning styles while also taking cognisance of nuances in practice.

Previous studies with Irish advanced paramedics and paramedics reinforce the concept of practical-type learning as a preferred methodology and as an effective way of maintaining skills $[7,35]$ and that skills practice is an integral part of maintaining competence [36]. Indeed, our results, in part, reinforce the focus of older/traditional basic training curricula for ambulance staff in the United Kingdom and Ireland, which for the most part, was skills-based [37]. This is quite different to results seen for other professions who tend to prefer attending conferences, lectures and reading of relevant journals $[9,12]$, even though there is little evidence to suggest that attending conferences had any direct impact on improving professional practice [38].

\section{CPC annual hours}

Internationally, there are similarities in the way in which CPC hours are recorded, most being based on an hoursrelated credit system, in which one hour of educational activity equates to one credit and the number of credit/ hours required vary from between 50-100 per year [30]. Irish doctors now, under the Medical Practitioners Act [27] must meet professional competence requirements [39] and this currently is 50 hours per year. In that context, the respondents in this survey believe that it would not be unreasonable to expect EMTs to complete 20-40 hours annually.

\section{Limitations}

The study had a number of strengths and weaknesses. The majority of respondents were male $70 \%(\mathrm{n}=272)$ in what is predominantly a male dominated profession in Ireland. At the time of the survey, there were 634 males registered with PHECC representing 69\% of all EMTs registered $(n=925)$. Thus, the sample of participants in this study was similar to the proportion of male EMTs registered with PHECC. 
The response to this survey was quite favourable, with a response rate of over $40 \%$. This too is perhaps not surprising and may be due to the fact that the EMTs surveyed, for the most part, were affiliated with the voluntary organisations and, by association, are enthusiastic volunteers who self-nominated to progress to EMT programmes and subsequent examinations.

Notably, one group of EMTs may not have participated. These are EMTs not affiliated to any organisation and who most likely completed the EMT training programme independently.

While the response to the survey was quite favourable, we acknowledge some methodological considerations may limit generalisability. For instance, while we report data from 399 responses, this represented $43 \%$ of all registered EMTs. Our study was limited to those with valid email addresses on the PHECC register and clearly those for whom the subject area was a priority. Therefore, it is possible that our sample may not be representative of EMTs in general. Furthermore, the fact that a significant number of respondents represented a younger population (with over $27 \%$ under the age of thirty years, and a further $30 \%$ under the age of forty years) may have influenced the results. Arguably, a younger population may prefer a blended learning approach with an active participation and e-learning combination given the possibility that they may be more familiar with on-line/e-learning experiences. Indeed, the length of the survey may have been perceived as too long or complex, thereby reducing the return rate. Further research following the introduction of CPC for EMTs may expand upon these findings.

\section{Conclusions}

To date, little research has been conducted with PHECC registered practitioners in general or on EMTs and CPD/ $\mathrm{C}$ internationally. This survey is the first to ascertain the opinions of EMTs regarding CPC in terms of what is being completed currently, and how it may be developed in Ireland in the coming years.

The results of this survey demonstrate, at the very least, emphasis will need to be placed on practical activities such as: Cardiac First Response, maintaining a portfolio of evidence, mentoring others, completing operational shifts with paramedics and advanced paramedics and a blended learning approach with e-learning.

Conversely, less emphasis should be placed on elearning alone and prudent purveyors of education for pre-hospital practitioners should emphasise inclusion of practical-type education.

There appears to be a genuine enthusiasm towards $\mathrm{CPC}$, with a large number of EMTs already completing $\mathrm{CPC}$ activities, maintaining a learning portfolio and maintaining their registration. Maintaining this motivation is an important facet of effective professional competence and development.

\section{Additional file}

Additional file 1: Emergency Medical Technician Continuous Professional Competence questionnaire.

\section{Competing interests}

The authors declare that they have no competing interests.

\section{Authors' contributions}

SK conceived of the study and was involved in the design, collection of data, data analysis, drafting the manuscript. WC and CD (principal investigator) were involved in the conception of the study, data analysis and interpretation and drafting the manuscript. All authors read, reviewed the manuscript critically for intellectual content, and approved the final manuscript.

\section{Authors' information}

Prof Colum Dunne, Chair \& Director of Research, Graduate Entry Medical School, University of Limerick, Limerick, Ireland. Tel: +353 (0)61 234703. Email: colum.dunne@ul.ie

SK: Education Manager, National Ambulance Service College, Dublin, Ireland. WC: Chair of General Practice, Graduate Entry Medical School, University of Limerick, Ireland.

CD: Chair \& Director of Research, Graduate Entry Medical School, University of Limerick, Ireland.

\section{Acknowledgements}

The authors thank the Registered EMTs who participated in the conference feedback session and those who gave their time to respond to the questionnaire. Thanks also to Dr Helen Purtill of the Statistical Consulting Unit, University of Limerick for her comments on the design and results of the survey and Dr. Niamh Cummins, from the Centre for Pre-Hospital Research (CPR) University of Limerick, for her comments on the results and manuscript.

\section{Author details}

${ }^{1}$ Centre for Interventions in Infection, Inflammation \& Immunity (4i) and Graduate Entry Medical School, University of Limerick, Limerick, Ireland. ${ }^{2}$ Health Services Executive, National Ambulance Service College, Dublin, Ireland.

Received: 12 July 2013 Accepted: 13 December 2013 Published: 17 December 2013

\section{References}

1. The pre-hospital emergency care council. http://www.phecit.ie.

2. Report of the review group on the ambulance service. http://hdl.handle.net/ $10147 / 81141$.

3. The pre-hosptial emergency care council strategic plan 2011-2014. http:// www.phecit.ie/Images/PHECC/Publications\%20and\%20Media/Strategic\% 20Plans/Strategic\%20Plan\%202011-2014.pdf.

4. Mooney S, Bury G: Cardiopulmonary resuscitation in a moving ambulance: is the one person over the head technique as effective as standard 2 person CPR? Resuscitation 2010, 81(2):S45.

5. Figgis $K$, Slevin $O$, Cunningham JB: Investigation of paramedics' compliance with clinical practice guidelines for the management of chest pain. Emerg Med J 2010, 27:151-155.

6. Bury G, Janes D, Bourke M, O'Donnell C: The advanced paramedic internship: an important clinical learning opportunity. Resuscitation 2007, 73:425-429.

7. Knox S, Cullen W, Collins N, Dunne C: First evaluation of CPD advanced paramedic teaching methods in Ireland. J Paramed Pract 2013, 5:29-35.

8. Henwood SM, Yielder J, Flinton D: Radiographers attitudes to mandatory CPD: a comparative study in the United Kingdom and New Zealand. Radiography 2004, 10:251-258. 
9. Timmins F: Cardiac nurses' views of continuing professional education. Eur J Cardiovasc Nurs 2008, 7:59-66.

10. Murphy C, Cross C, Mc Guire D: The motivation of nurses to participate in continuing professional education in Ireland. J Eur Indus Train 2006, 30:365-384

11. Ryan J: Continuous professional development along the continuum of lifelong learning. Nurse Educ Today 2003, 23:498-508.

12. Schostak J, Davis M, Hanson J, Brown T, Driscoll P, Starke I, Jenkins N: 'Effectiveness of continuing professional development' project: a summary of findings. Med Teach 2010, 32:586-592.

13. Report on the continuing professional development of staff nurses and staff midwives. http://www.lenus.ie/hse/handle/10147/44776

14. Colthart I, Bagnall G, Evans A, Allbutt H, Haig A, Illing J, McKinstry B: The effectiveness of self-assessment on the identification of learner needs, learner activity, and impact on clinical practice: BEME Guide no. 10. Med Teach 2008, 30:124-145.

15. Ward M, Gruppen L, Regehr G: Measuring self-assessment: current state of the art. Adv Health Sci Educ 2002, 7:63-80

16. International resuscitation conference and skills showcase. http://www.resus. ie/timetable.html.

17. Mindgenius. http://www.mindgenius.com/?_kk=MindGenius\&_kt=8020e02227bc-4aeb-a373-b4e2397393e4.

18. Norum J, Elsbak T: The ambulance services in northern Norway 20042008: improved competence, more tasks, better logistics and increased costs. Int J Emerg Med 2010, 3:69-74.

19. Paramedic professional competency standards project report. http://caa.net.au/ downloads/Standards_Report.pdf.

20. Health and Care Professions Council UK: Continuing professional development and your registration. http://www.hpc-uk.org/assets/ documents/10001314CPD_and_your_registration.pdf.

21. National occupational competency profile for paramedics. http://paramedic. ca/wp-content/uploads/2012/12/2011-10-31-Approved-NOCP-EnglishMaster.pdf.

22. Martin J: The challenge of introducing continuous professional development for paramedics. J Emerg Prim Healthc 2006, 4:8,

23. Bassendowski S, Petrucka P: Perceptions of select registered nurses of the continuing competence program of the saskatchewan registered nurses' association. J Contin Educ Nurs 2009, 40:553-559.

24. Chong MC, Sellick K, Francis K, Abdullah KL: What influences Malaysian nurses to participate in continuing professional education activities? Asian Nurs Res 2011, 5:38-47.

25. Sturrock JBE, Lennie SC: Compulsory continuing professional development: a questionnaire-based survey of the UK dietetic profession. J Hum Nutr Diet 2009, 22:12-20.

26. Haughey SL, Hughes CM, Adair CG, Bell HM: Introducing a mandatory continuing professional development system: an evaluation of pharmacists' attitudes and experiences in Northern Ireland. Int I of Pharm Pract 2007, 15:243-249.

27. Medical practitioners act. http://www.irishstatutebook.ie/pdf/2007/en. act.2007.0025.pdf.

28. National registration and accreditation scheme for the health professions. http://www.ahwo.gov.au/documents/National\%20Registration\%20and\% 20Accreditation/NATREG\%20-\%20Intergovernmental\%20Agreement.pdf.

29. Statutory registration for health and social professionals. http://www.dohc.ie/ publications/pdf/statreg.pdf?direct=1.

30. Peck C, McCall M, McLaren B, Rotem T: Continuing medical education and continuing professional development: international comparisons. BMJ 2000, 320:432-435.

31. Ruiz JG, Mintzer MJ, Leipzig RM: The impact of E-learning in medical education. Acad Med 2006, 81:207-212.

32. Evaluation of the an bord altranais category 1 approval policy and process. http://www.nursingboard.ie/en/publications_current.aspx.

33. Irish medical council. http://www.medicalcouncil.ie/Education-and-Training/

34. Woollard M: The role of the paramedic practitioner in the UK. J Emerg Prim Healthc 2006, 4:9p.

35. Simpson PM, Bendall JC, Patterson J, Middleton PM: Beliefs and expectations of paramedics towards evidence-based practice and research. Int J Evid Based Healthc 2012, 10:197-203.

36. Nasim S, Maharaj C, Malik M, O' Donnell J, Higgins B, Laffey J: Comparison of the glidescope (R) and pentax AWS (R) laryngoscopes to the macintosh laryngoscope for use by advanced paramedics in easy and simulated difficult intubation. BMC Emerg Med 2009, 9:9.

37. Kilner T: Desirable attributes of the ambulance technician, paramedic, and clinical supervisor: findings from a Delphi study. Emerg Med J 2004, 21:374-378

38. Mansouri M, Lockyer J: A meta-analysis of continuing medical education effectiveness. J Contin Educ Health Prof 2007, 27:6-15.

39. Professional competence requirements. http://www.medicalcouncil.ie/ Information-for-Doctors/Professional-Competence-FAQ/Professionalcompetence-requirements.html.

doi:10.1186/1471-227X-13-25

Cite this article as: Knox et al: Continuous professional competence (CPC) for emergency medical technicians in Ireland: educational needs assessment. BMC Emergency Medicine 2013 13:25.

\section{Submit your next manuscript to BioMed Central and take full advantage of:}

- Convenient online submission

- Thorough peer review

- No space constraints or color figure charges

- Immediate publication on acceptance

- Inclusion in PubMed, CAS, Scopus and Google Scholar

- Research which is freely available for redistribution 